\title{
Pathology and genetics of phaeochromocytoma and paraganglioma
}

\author{
John Turchini, ${ }^{1,2,3}$ Veronica K Y Cheung, ${ }^{1,3}$ Arthur S Tischler, ${ }^{4}$ Ronald R De Krijger ${ }^{5,6}$ \& \\ Anthony J Gill ${ }^{1,2,3}$ \\ ${ }^{1}$ Cancer Diagnosis and Pathology Group, Kolling Institute of Medical Research, Royal North Shore Hospital, St \\ Leonards, NSW, Australia, ${ }^{2}$ University of Sydney, Sydney, NSW, Australia, ${ }^{3}$ Department of Anatomical Pathology, \\ NSW Health Pathology, Royal North Shore Hospital, St Leonards, NSW, Australia, ${ }^{4}$ Department of Pathology and \\ Laboratory Medicine Tufts Medical Center, Tufts University School of Medicine, Boston, MA, USA, ${ }^{5}$ Department of \\ Pathology, Erasmus MC Cancer Institute, University Medical Center Rotterdam, Rotterdam, The Netherlands, and \\ ${ }^{6}$ Department of Pathology, Reinier de Graaf Hospital, Delft, The Netherlands
}

Turchini J, Cheung V K Y, Tischler A S, De Krijger R R \& Gill A J

(2018) Histopathology 72, 97-105. https://doi.org/10.1111/his.13402

\section{Pathology and genetics of phaeochromocytoma and paraganglioma}

Phaeochromocytoma and paraganglioma (PHEO/PGL) are rare tumours with an estimated annual incidence of 3 per million. Advances in molecular understanding have led to the recognition that at least 30-40\% arise in the setting of hereditary disease. Germline mutations in the succinate dehydrogenase genes SDHA, SDHB, SDHC, SDHD and SDHAF2 are the most prevalent of the more than 19 hereditary genetic abnormalities which have been reported. It is therefore recommended that, depending on local resources and availability, at least some degree of genetic testing should be offered to all PHEO/PGL patients, including those with clinically sporadic disease. It is now accepted that that all PHEO/PGL have some metastatic potential; therefore, concepts of benign and malignant PHEO/PGL have no meaning and have been replaced by a risk stratification approach. Although there is broad acceptance that certain features, including high proliferative activity, invasive growth, increased cellularity, large tumour nests and comedonecrosis, are associated with an increased risk of metastasis, it remains difficult to predict the clinical behaviour of individual tumours and no single risk stratification scheme is endorsed or in widespread use. In this review, we provide an update on advances in the pathology and genetics of PHEO/ PGL with an emphasis on the changes introduced in the WHO 2017 classification of endocrine neoplasia relevant to practising surgical pathologists.

Keywords: multiple endocrine neoplasia type 2, paraganglioma, phaeochromocytoma, succinate dehydrogenase, von Hippel-Lindau syndrome

\section{Introduction}

The accurate pathological diagnosis of phaeochromocytoma and paraganglioma (PHEO/PGL) has never been more important, not only because correct

Address for correspondence: A J Gill, Department of Anatomical Pathology, Royal North Shore Hospital, Pacific Highway St Leonards, NSW 2065, Australia. e-mail: affgill@med.usyd.edu.au diagnosis underpins both clinical management and translational research, but particularly because of a new understanding of the strongly hereditary nature of these tumours. It is now accepted that at least 30$40 \%$ of PHEO/PGL arise in the context of hereditary disease, and cascade testing of index patients facilitates risk reduction strategies across entire kindreds. ${ }^{1,2}$ In this review we provide an update on the pathology and genetics of PHEO/PGL based on 
current concepts in the fourth edition 2017 World Health Organisation (WHO) classification of tumours of endocrine organs. ${ }^{1}$

\section{Terminology}

By convention, tumours arising in the adrenal medulla are referred to as phaeochromocytomas, whereas morphologically indistinguishable tumours arising from the chromaffin cells of the autonomic nervous system outside the adrenal medulla are termed paraganglioma. ${ }^{1}$ That is, the distinction between phaeochromocytoma and paraganglioma is somewhat arbitrary - particularly because the adrenal medulla is considered the largest paraganglion in the body. Paragangliomas can be subdivided further into sympathetic and parasympathetic subtypes on the basis of function and location. Sympathetic paragangliomas typically arise along the sympathetic chains in the thorax and abdomen. Parasympathetic paragangliomas originate from the parasympathetic autonomic nervous system, usually in the head and neck, and are associated with the cranial nerves. ${ }^{1,3,4}$

As a group, germline mutations in the autosomal genes which encode the succinate dehydrogenase (SDH) enzymes [succinate dehydrogenase complex subunit A (SDHA), succinate dehydrogenase complex subunit B $(S D H B)$, succinate dehydrogenase complex subunit $\mathrm{C}(S D H C)$, succinate dehydrogenase complex subunit D (SDHD) and succinate dehydrogenase complex assembly factor 2 (SDHAF2)] are now recognised to be the most frequent cause of hereditary PHEO/PGL, perhaps accounting for up to half of germline mutations in phaeochromocytomas and paragangliomas (Figure 1). ${ }^{5-8}$ As succinate dehydrogenase deficient neoplasia is the topic of a separate review in this journal, ${ }^{8}$ the $S D H$ genes and associated neoplasms as well as the utility of SDHB and SDHA immunohistochemistry as a screening test for these mutations are not discussed further in this paper. The next most common germline mutations are those associated with von Hippel-Lindau syndrome (VHL), multiple endocrine neoplasia type 2 (RET) and neurofibromatosis type 1 (NF1). ${ }^{1}$ However, it is now known that germline mutations in many other genes, most of which are individually rare, can also lead to hereditary tumour syndromes which manifest with PHEO/PGL. At the time of writing these genes include EPAS1, TMEM127, MAX, KIF1B $\beta$, PHD2, FH, MDH2 and MEN1. ${ }^{1,2,4,6,9-}$ 11 The genetic mutations which may present with PHEO/PGL and associated syndromes as reported in the WHO 2017 classification are summarised in Table 1 and their relative incidences are presented in Figure $1 .^{1}$

\section{Incidence and location}

It is important to recognise that PHEO/PGL are rare tumours with a reported estimated annual incidence of up to 3 per million, with paragangliomas

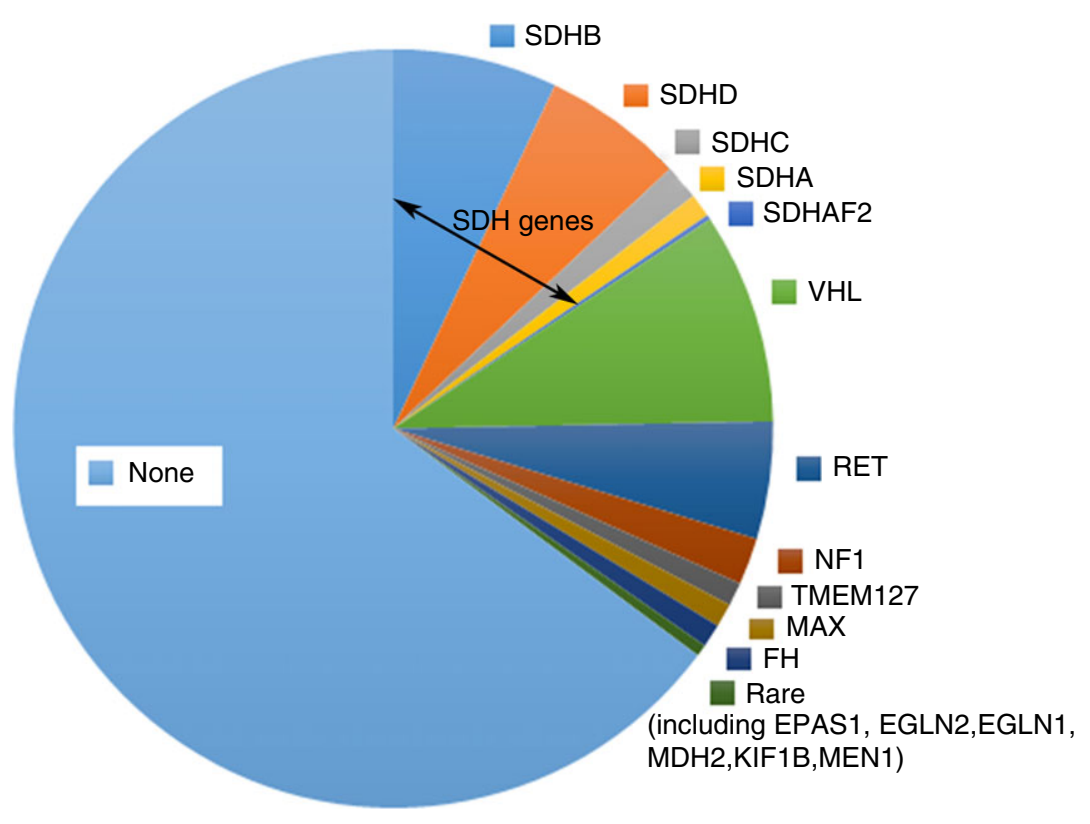

Figure 1. Frequency of different germline mutations in patients presenting with phaeochromcoytoma and paraganglioma. 
probably outnumbering phaeochromocytoma by twofold. 1,7,8,12-16 Phaeochromocytomas may occur at any age; however, the median age at presentation is the 4 th-5th decades with an equal gender distribution. ${ }^{1,17}$ Phaeochromocytoma presenting in young patients are significantly more likely to be hereditary, particularly in children where germline mutations have been reported in at least $70 \%$ of patients. ${ }^{18-20}$

Parasympathetic paragangliomas occur predominantly in the head and neck, where they account for approximately $0.6 \%$ of all neoplasms., ${ }^{1,21,22}$ The reported age range is wide, and the mean age is 44 years. $^{23,24}$ There is a strong female predominance, with female to male ratios reported to be as high as $8: 1 .^{25,26}$ The tumours are frequently bilateral or multiple which, together with a younger age of onset, are clear clues to hereditary disease. ${ }^{24,27-29}$ Head and neck paragangliomas, being parasympathetic, are very rarely functional. ${ }^{1}$ Compared to other sites, metastasis from head and neck paragangliomas is relatively rare. ${ }^{1,24,30}$

Although $12 \%$ arise in the thorax (with $2 \%$ being associated with the heart), the majority of sympathetic paragangliomas occur below the diaphragm, particularly in close proximity to the adrenal gland (42\%), organ of Zuckerkandl (28\%) and bladder $(10 \%)^{1,31-40}$ Unlike their predominantly head and neck parasympathetic counterparts there is an equal gender distribution, with the most common age at presentation being the fifth decade but with a younger age of onset in hereditary disease. ${ }^{1,41}$ The reported incidence of metastasis from sympathetic paragangliomas is highly variable, and ranges from $2.5 \%$ to $50 \%$ in some series. ${ }^{42-44}$ However, it is generally recognised that intra-abdominal extra-adrenal paragangliomas have a higher rate of metastasis, perhaps because of a strong association with germline SDHB mutation. ${ }^{7,8}$

\section{Clinical presentation and detection}

Phaeochromocytomas and paragangliomas can be either functional, i.e. they secrete catecholamines, or non-functional, in which case they present usually as a mass and are found incidentally on imaging performed for other reasons. The catecholamines that are produced are either methylated (inactivated) or unmethylated. $^{1}$ Functional tumours that secrete unmethylated catecholamines produce symptoms related to catecholamine synthesis. In addition to the classic triad of sweating, palpitations and headache, which is found in only the minority of patients, symptoms associated with functional PHEO/PGL may include paroxysmal or persistent hypertension, pallor, anxiety, panic attacks, tremor or constipation. 1,15,19 Non-catecholamine-associated paraneoplastic syndromes have been reported, and include hypercalcaemia, cytokine secretion, human placental lactogen secretion, vasoactive intestinal peptide secretion and Cushing's syndrome due to ectopic adrenocorticotrophic hormone (ACTH) or, very rarely, corticotrophin-releasing hormone $(\mathrm{CRH})$ production. ${ }^{45,46}$ Unlike phaeochromocytomas, sympathetic paragangliomas secrete adrenaline very rarely, as the elevated levels of glucocorticoid needed for the enzymatic conversion of noradrenaline to adrenaline are absent. 1,47-49 Thus, the little over half of all sympathetic paragangliomas which are functional secrete noradrenaline or dopamine. ${ }^{4-49}$ The biochemical profile can be used to suggest the location of PHEO/ PGL, which can be confirmed by anatomical imaging [(ultrasound, computerised tomography (CT), magnetic resonance imaging (MRI)] and functional imaging [123I-MIBG scintigraphy and DOTATATE positron emission tomography $(\mathrm{PET}) / \mathrm{CT}] .{ }^{1,50-52}$ The biochemical profile can also be a clue to hereditary disease, as multiple endocrine neoplasia type 2 (MEN2) or neurofibromatosis type 1-associated tumours are more likely to produce adrenaline, whereas noradrenaline-producing tumours are associated more frequently with von Hippel-Lindau syndrome, while elevated levels of 3-methoxytyramine may suggest germline succinate dehydrogenase mutation. ${ }^{49,53,54}$

It is important to remember that clinically nonfunctional tumours may or may not be biochemically functional. Biochemical function, i.e. the ability to produce catecholamines or their metabolites, requires the expression of tyrosine hydroxylase (TH), the initial enzyme in catecholamine biosynthesis. Immunohistochemical stains for $\mathrm{TH}$ are positive in most sympathetic paragangliomas, but in only a minority of parasympathetic paragangliomas. ${ }^{55} \mathrm{~A}$ $\mathrm{TH}$ stain of a paraganglioma, particularly in the head or neck, can be useful because recurrence or persistence of catecholamine metabolites in a patient whose tumour is TH-negative most probably indicates a second primary rather than recurrence or metastasis.

\section{Morphology}

PHEO/PGL may show a variety of architectural patterns (Figures 2-4), but generally these have little 
Table 1. Genes and tumour associations of hereditary phaeochromocytoma (PCC), paranganglioma (PGL) of head and neck $(H \& N)$ and of abdomen or thorax $(A / T)^{1}$

\begin{tabular}{|c|c|c|c|c|}
\hline Gene & $\begin{array}{l}\text { Chromosome } \\
\text { location }\end{array}$ & Syndrome & Distribution & Tumour associations \\
\hline$S D H D$ & $11 q 23$ & PGL1/CSS & $\mathrm{PGL}>\mathrm{PCC}$ & $\begin{array}{l}\text { SDH-deficient GIST, pituitary adenoma, ?SDH-deficient } \\
\text { RCC }\end{array}$ \\
\hline SDHAF2 & $11 q 12.2$ & PGL2/CSS & PGL H\&N & Unknown/not reported \\
\hline$S D H C$ & $1 \mathrm{q} 23.3$ & PGL3/CSS & PGL H\&N & SDH-deficient RCC and GIST \\
\hline$S D H B$ & $1 p 36.13$ & PGL4/CSS & $\begin{array}{l}\mathrm{PGL} A / T \gg P G L \\
\mathrm{H} \& N>P C C\end{array}$ & SDH-deficient RCC and GIST, pituitary adenoma \\
\hline$S D H A$ & $5 p 15.33$ & PGL5/CSS & $\mathrm{PGL}>\mathrm{PCC}$ & Pituitary adenoma, SDH-deficient RCC and GIST \\
\hline$V H L$ & $3 p 25.5$ & VHL & PCC $\gg>P G L$ & $\begin{array}{l}\text { Clear cell RCC, haemangioblastoma; NETs, pancreatic } \\
\text { serous cystadenoma }\end{array}$ \\
\hline RET & $10 q 11.2$ & MEN2 & PCC $\gg>P G L$ & $\begin{array}{l}\text { Medullary thyroid carcinoma, parathyroid hyperplasia/ } \\
\text { adenoma, mucocutaneous manifestations }\end{array}$ \\
\hline NF1 & $17 q 11.2$ & NF1 & PCC $\gg>P G L$ & $\begin{array}{l}\text { Neurofibroma and MPNST, oculocutaneous } \\
\text { manifestations, duodenal NET }\end{array}$ \\
\hline TMEM127 & $2 q 11.2$ & & $\mathrm{PCC}>\mathrm{PGL}$ & $\mathrm{RCC} ?$ \\
\hline EPAS1 & $2 \mathrm{p} 21$ & PZS & $\mathrm{PCC} \sim \mathrm{PGL} \mathrm{A} / \mathrm{T}$ & Duodenal NET, polycythaemia, ocular manifestations \\
\hline EGLN2 & $19 q 13.2$ & & $\mathrm{PCC} \sim \mathrm{PGL} \mathrm{A} / \mathrm{T}$ & Polycythaemia \\
\hline EGLN1 & $1 \mathrm{q} 42.1$ & & $\mathrm{PCC} \sim \mathrm{PGL} A / \mathrm{T}$ & Polycythaemia \\
\hline MAX & $14 q 23.3$ & & $\mathrm{PCC} \sim \mathrm{PGL}$ & Unknown/not reported \\
\hline $\mathrm{FH}$ & $1 \mathrm{q} 42.1$ & HLRCC & $\mathrm{PCC} \sim \mathrm{PGL}$ & $\begin{array}{l}\text { Cutaneous and uterine fumarate hydratase deficient } \\
\text { leiomyoma, HLRCC-associated RCC }\end{array}$ \\
\hline$M D H 2$ & $7 q 11.23$ & & PGL A/T & Unknown/not reported \\
\hline KIF1B & $1 \mathrm{p} 36.22$ & & & $\begin{array}{l}\text { Ganglioneuroma, leiomyosarcoma, lung adenocarcinoma, } \\
\text { neuroblastoma, ganglioneuroma }\end{array}$ \\
\hline MEN1 & $11 q 13.1$ & & $\mathrm{PCC} \sim \mathrm{PGL} \mathrm{H \& N}$ & $\begin{array}{l}\text { Pancreatic NET, bronchopulmonary and thymic NET, } \\
\text { parathyroid adenoma/hyperplasia, pituitary adenoma }\end{array}$ \\
\hline
\end{tabular}

CSS, Carney-Stratakis syndrome; GIST, Gastrointesintal stromal tumour; HLRCC, Hereditary leiomyomatosis and renal cell carcinoma; MEN2, Multiple endocrine neoplasia type 2; MPNST, Malignant peripheral nerve sheath tumour; NET, Neuroendocrine tumour; NF1, Neurofibromatosis type 1; PA, Pituitary adenoma; PGL1-5, Paraganglioma syndrome types 1-5; PZS, Pacak-Zhuang syndrome; RCC, Renal cell carcinoma; SDH, Succinate dehydrogenase; VHL, von Hippel-Lindau syndrome.

clinical significance. ${ }^{56-59}$ The classic pattern shows nests of cells ('Zellballen') with prominent surrounding capillaries. Trabecular or solid architecture may also be present, and different patterns may be intermixed in the same tumour. Composite tumours, usually consisting of PHEO/PGL combined with ganglioneuroblastoma or ganglioneuroma, are seen occasionally. The presence of a few isolated ganglion cells may be a clue to the presence of composite features, but on its own are insufficient to warrant the diagnosis of a composite phaeochromocytoma which requires the presence of a well-developed second component. $^{1,46}$

Previously, small areas of expansion of the adrenal medulla less than $10 \mathrm{~mm}$ in diameter were considered hyperplastic medullary nodules. These small lesions, usually recognised only in the setting of hereditary disease, have been proved to be clonal and are now considered true pheochromocytomas. ${ }^{1,56}$ Although a formal nomenclature change was not made in WHO 2017, the term "microphaeochromocytoma' would not be inappropriate. 
Figure 2. Phaeochromocytoma arising in an adrenal gland. A, Low-power view showing surrounding residual cortex [haematoxylin and eosin (H\&E)]; B, high-power view showing typical nuclear morphology (H\&E).
Figure 3. The variable morphology of phaeochromocytoma and paraganglioma. A, Prominent vascular spaces [haematoxylin and eosin (H\&E)]; B, typical nested growth pattern with sustentacular cells (H\&E); C early fibrosis in an area of ischaemia and atrophy (H\&E); D, diffuse and nodular growth (H\&E).

Figure 4. Paraganglioma arising in association with a large vein $[\mathbf{A}$, haematoxylin and eosin (H\&E); B, H\&E].
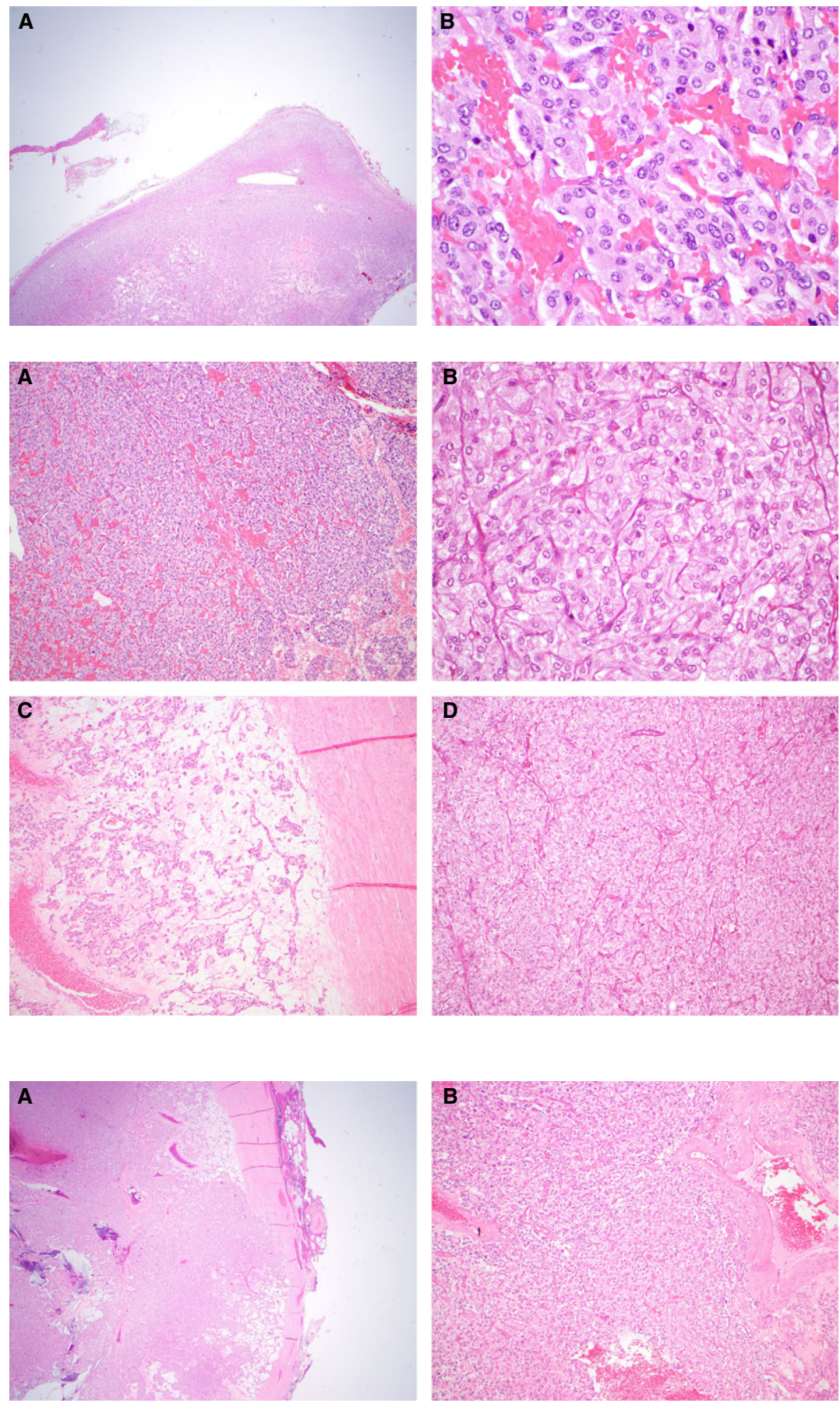

\section{Risk stratification and pathological parameters}

In the third edition of the WHO classification from 2004, PHEO/PGLs were classified as malignant or benign on the basis of unequivocal metastatic disease, defined by the confirmation of metastatic tumour in a site that does not normally have a chromaffin cell population. Generally speaking, sites that qualify for metastasis are bone, lung, liver and histologically confirmed lymph node. Modern understanding, as reflected in the fourth edition WHO classification from 2017, is that all PHEO/PGL have some metastatic potential. ${ }^{1}$ Although the risk of metastasis may be very low in a completely resected, adrenal-confined phaeochromocytoma the risk is not zero, and it is 
therefore inappropriate to consider such a tumour as 'benign'. Therefore, the qualifiers of 'benign' or 'malignant' have no meaning in the context of PHEO/ PGL and have been replaced by a concept of risk stratification with the implicit understanding that all PHEO/PGL have the potential to metastasise, but some possess higher risk than others. In general, risk is higher for sympathetic paraganglioma than phaeochromocytoma or parasympathetic paraganglioma. Tumours larger than $5 \mathrm{~cm}$ are also associated with increased risk. ${ }^{60}$

Various histological features in a primary PHEO/ PGL have been reported to be associated with an increased risk of subsequent metastasis. These include invasion of soft tissue and blood vessels; particular architectural patterns including hypercellularity and large confluent nests; comedo-type necrosis; and a high mitotic count or Ki-67 proliferative index. ${ }^{60-63}$ Less well-accepted factors which may connote an increased risk of metastasis include coarse nodularity, decreased numbers of sustentacular cells or the absence of hyaline globules. ${ }^{60,64-66}$

While there is widespread acceptance that some factors are associated with an increased risk of metastasis, it is difficult to quantify this risk in individual patients. Several grading schemes based on weighted composite scores of combinations of these factors have been proposed, with the most well-known being the Phaeochromocytoma of the Adrenal Scaled (PASS) score $^{62}$ and the Grading system for Adrenal Phaeochromocytoma and Paraganglioma (GAPP) score. ${ }^{61,67}$ The PASS score seeks to give a threshold whereby all tumours over and above a set score are 'at risk' of metastasis (and, by implication, all tumours below this score at very low risk), whereas the GAPP score gives a scale of risk of metastasis and a likelihood of survival. ${ }^{61,67}$ However, at the time of writing, both systems are underexamined and require validation in large independent cohorts before they can be endorsed for routine clinical use.

One interesting aspect of the histological examination is the potential role to suggest patients with hereditary disease and specific mutations. Small tumour cells, the presence of a myxoid component and a vascular pseudocapsule are suggestive of von-Hippel Lindau (VHL) disease, ${ }^{1,68}$ whereas medullary hyperplasia with multiple tumours is more in keeping with MEN2,,69 and rounded epithelioid cells sometimes with relatively clear cytoplasm, in tightly nested balls surrounded by a welldeveloped capillary vasculature, may be associated with succinate dehydrogenase mutation. ${ }^{8}$ The presence or absence of these features is prone to interobserver variability, and in no way replaces molecular testing. ${ }^{1,70}$

The pathological differential diagnosis of PHEO/ PGL includes adrenal cortical oncocytic tumours, renal cell carcinomas and low-grade neuroendocrine tumours (NETs, known previously as carcinoids). ${ }^{71}$ Our experience has been that oncocytic adrenal cortical tumours are the most common mimicker of adrenal phaeochromocytomas and NETs are the most common mimicker of paragangliomas. Knowledge that virtually all PHEO/PGL express chromogranin A can be particularly useful to resolve certain differential diagnoses. ${ }^{46,72}$ However, pitfalls in the interpretation of immunohistochemistry include the fact that oncocytic phaeochromocytomas are more likely to express chromogranin A only weakly, and that PHEO/PGLs may rarely show immunoreactivity for MelanA, inhibin or cytokeratin. ${ }^{71,73}$ S100 may be useful to highlight sustentacular cells; however, they are not infrequently absent $^{74}$ and our experience has been that neoplastic cells in many PHEO/PGL also express S100. The use of keratins may distinguish NETs from PHEO/ PGL, as the latter have only focal and/or weak expression, whereas NETs usually show diffuse and strong expression. However, keratins are not very useful for the distinction of PHEO/PGL and adrenocortical tumours. The latter, however, can be stained reliably with the relatively new specific marker steroidogenic factor-1 (SF1). ${ }^{75}$

\section{Genetics}

As patients with phaeochromocytoma have at least a $30-40 \%$ chance of hereditary disease, it is now recommended that all patients undergo at least some degree of genetic screening. ${ }^{1,49}$ With the rise of a panel approach to molecular testing, to a large extent the degree of genetic testing undertaken may depend more upon local availability and resources than the pretest probability of hereditary disease on the basis of age of onset, multifocality and family history. It is emphasised that in some studies up to $24 \%$ of patients with clinically sporadic PHEO/PGL have been shown to have hereditary disease, and therefore the absence of a family history or other syndromic manifestations in no way excludes the need for genetic testing. ${ }^{1,76-79}$ The mode of inheritance is most commonly autosomal-dominant and associated with inactivating mutations or deletions in tumour suppressor genes. However, RET, EPAS1 and HIF $2 A$ genes carry gain-of-function mutations. ${ }^{79}$ Some mutations, including MAX, SDHAF2 and SDHD, show a parent- 
of-origin effect requiring paternal transmission for clinical disease, but not for the carrier state. ${ }^{1}$

Recurrent somatic mutations in the same genes which cause hereditary disease are being recognised increasingly, and somatic mutations can be detected in up to $20 \%$ of patients in one of the genes associated with hereditary susceptibility, most frequently NF1. ${ }^{1,80,81}$ Recurrent somatic mutations in BRAF and HRAS are reported in up to $8.9 \% .^{1,79-81}$ While mutations are a requirement for tumorigenesis, additional genetic abnormalities need to be present. The frequent loss of particular chromosomal regions, including 1p, 3q, 11p, 11q, 6q, 17p, 9q, 17q, $19 \mathrm{p} 13.3$ and 20q, has suggested the presence of tumour suppressor genes within these loci; however, to date no recurrent specific gene mutations have been identified at these sites. ${ }^{1,81}$

\section{Conclusion}

In conclusion, PHEO/PGLs are rare tumours which are important to recognise. Recent conceptual changes include the replacement of the qualifiers 'benign' and 'malignant' with the recognition that all PHEO/PGL have a metastatic risk and an approach based on risk stratification. Additionally, the very strong hereditary basis of this tumour is now emphasised, and there is an accompanying recommendation that at least some degree of genetic testing should be offered to all PHEO/PGL patients.

\section{Conflict of Interests}

The authors declare no conflicts of interest.

\section{References}

1. Kloeppel G, Lloyd R, Osamura R, Roasi J eds. Pathology and genetics of endocrine organs, 4th edn. Lyon: IARC Press, 2017; 179-195.

2. Boedeker CC, Hensen EF, Neumann HP et al. Genetics of hereditary head and neck paragangliomas. Head Neck 2014; 36; 907-916.

3. Erickson D, Kudva YC, Ebersold MJ et al. Benign paragangliomas: clinical presentation and treatment outcomes in 236 patients. J. Clin. Endocrinol. Metab. 2001; 86; 5210-5216.

4. Zheng X, Wei S, Yu Y et al. Genetic and clinical characteristics of head and neck paragangliomas in a Chinese population. Laryngoscope 2012; 122; 1761-1766.

5. Giubellino A, Lara K, Martucci V et al. Urinary bladder paragangliomas: how immunohistochemistry can assist to identify patients with SDHB germline and somatic mutations. Am. J. Surg. Pathol. 2015; 39; 1488-1492.
6. Pasini B, Stratakis CA. SDH mutations in tumorigenesis and inherited endocrine tumours: lesson from the phaeochromocytoma-paraganglioma syndromes. J. Intern. Med. 2009; 266; $19-42$.

7. Gill AJ. Succinate dehydrogenase (SDH) and mitochondrial driven neoplasia. Pathology 2012; 44; 285-292.

8. Gill AJ. Succinate dehydrogenase (SDH)-deficient neoplasia. Histopathology 2017; 72; 106-116.

9. Dénes J, Swords F, Rattenberry E et al. Heterogeneous genetic background of the association of pheochromocytoma/paraganglioma and pituitary adenoma: results from a large patient cohort. J. Clin. Endocrinol. Metab. 2015; 100; E531-E541.

10. Currás-Freixes M, Inglada-Pérez L, Mancikova V et al. Recommendations for somatic and germline genetic testing of single pheochromocytoma and paraganglioma based on findings from a series of 329 patients. J. Med. Genet. 2015; 52; 647-656.

11. Burnichon N, Vescovo L, Amar L et al. Integrative genomic analysis reveals somatic mutations in pheochromocytoma and paraganglioma. Hum. Mol. Genet. 2011; 20; 3974-3985.

12. Andersen GS, Toftdahl DB, Lund JO, Strandgaard S, Nielsen PE. The incidence rate of phaeochromocytoma and Conn's syndrome in Denmark, 1977-1981. J. Hum. Hypertens. 1988; 2; 187-189.

13. Fernández-Calvet L, García-Mayor RV. Incidence of pheochromocytoma in South Galicia, Spain. J. Intern. Med. 1994; 236; 675-677.

14. Holland J, Chandurkar V. A retrospective study of surgically excised phaeochromocytomas in Newfoundland, Canada. Ind. J. Endocrinol. Metab. 2014; 18; 542-545.

15. Baguet JP, Hammer L, Mazzuco TL et al. Circumstances of discovery of phaeochromocytoma: a retrospective study of 41 consecutive patients. Eur. J. Endocrinol. 2004; 150; 681-686.

16. Oshmyansky AR, Mahammedi A, Dackiw A et al. Serendipity in the diagnosis of pheochromocytoma. J. Comput. Assist. Tomogr. 2013; 37; 820-823.

17. Weinhäusel A, Behmel A, Ponder BA et al. Long-term follow up of a 'sporadic' unilateral pheochromocytoma revealing multiple endocrine neoplasia MEN2A in an elderly woman. Endocr. Pathol. 2003; 14; 375-382.

18. Waguespack SG, Rich T, Grubbs E et al. A current review of the etiology, diagnosis, and treatment of pediatric pheochromocytoma and paraganglioma. J. Clin. Endocrinol. Metab. 2010; 95; 2023-3718.

19. Pamporaki C, Hamplova B, Peitzsch M et al. Characteristics of pediatric vs adult pheochromocytomas and paragangliomas. J. Clin. Endocrinol. Metab. 2017; 102; 1122-1132.

20. Young WF, Maddox DE. Spells: in search of a cause. Mayo Clin. Proc. 1995; 70; 757-765.

21. Mannelli M, Castellano M, Schiavi F et al. Clinically guided genetic screening in a large cohort of italian patients with pheochromocytomas and/or functional or nonfunctional paragangliomas. J. Clin. Endocrinol. Metab. 2009; 94; 1541-1547.

22. Sykes JM, Ossoff RH. Paragangliomas of the head and neck. Otolaryngol. Clin. North Am. 1986; 19; 755-767.

23. Chapman DB, Lippert D, Geer CP et al. Clinical, histopathologic, and radiographic indicators of malignancy in head and neck paragangliomas. Otolaryngol. Head Neck Surg. 2010; 143; 531-537.

24. Mediouni A, Ammari S, Wassef M et al. Malignant head/neck paragangliomas. Comparative study. Eur. Ann. Otorhinolaryngol. Head Neck Dis. 2014; 131; 159-166.

25. Lee JH, Barich F, Karnell LH et al. National Cancer Data Base report on malignant paragangliomas of the head and neck. Cancer 2002; 94; 730-737. 
26. Rodríguez-Cuevas S, López-Garza J, Labastida-Almendaro S. Carotid body tumors in inhabitants of altitudes higher than 2000 meters above sea level. Head Neck 1998; 20; 374-378.

27. Capatina C, Ntali G, Karavitaki N, Grossman AB. The management of head-and-neck paragangliomas. Endocr. Relat. Cancer 2013; 20; R291-R305.

28. Burnichon N, Rohmer V, Amar L et al. The succinate dehydrogenase genetic testing in a large prospective series of patients with paragangliomas. J. Clin. Endocrinol. Metab. 2009; 94; 2817-2827.

29. Moskovic DJ, Smolarz JR, Stanley D et al. Malignant head and neck paragangliomas: is there an optimal treatment strategy? Head Neck Oncol. 2010; 2; 23.

30. Garnier S, Réguerre Y, Orbach D, Brugières L, Kalfa N. Pediatric pheochromocytoma and paraganglioma: an update. Bull. Cancer 2014; 101; 966-975.

31. Henderson SJ, Kearns PJ, Tong CM et al. Patients with urinary bladder paragangliomas: a compiled case series from a literature review for clinical management. Urology 2015; 85; e25e29.

32. Quist EE, Javadzadeh BM, Johannesen E, Johansson SL, Lele SM, Kozel J. Malignant paraganglioma of the bladder: a case report and review of the literature. Pathol. Res. Pract. 2015; 211; $183-188$.

33. Wang JG, Han J, Jiang T, Li YJ. Cardiac paragangliomas. J. Card. Surg. 2015; 30: 55-60.

34. Millar AC, Mete O, Cusimano RJ et al. Functional cardiac paraganglioma associated with a rare SDHC mutation. Endocr. Pathol. 2014; 25; 315-320.

35. Zhou M, Epstein JI, Young RH. Paraganglioma of the urinary bladder: a lesion that may be misdiagnosed as urothelial carcinoma in transurethral resection specimens. Am. J. Surg. Pathol. 2004; 28; 94-100.

36. Opotowsky AR, Moko LE, Ginns J et al. Pheochromocytoma and paraganglioma in cyanotic congenital heart disease. $J$. Clin. Endocrinol. Metab. 2015; 100; 1325-1334.

37. Lima J, Feijão T, Ferreira da Silva A et al. High frequency of germline succinate dehydrogenase mutations in sporadic cervical paragangliomas in northern Spain: mitochondrial succinate dehydrogenase structure-function relationships and clinicalpathological correlations. J. Clin. Endocrinol. Metab. 2007; 92; 4853-4864.

38. Neumann HP, Erlic Z, Boedeker CC et al. Clinical predictors for germline mutations in head and neck paraganglioma patients: cost reduction strategy in genetic diagnostic process as fall-out. Cancer Res. 2009; 69; 3650-3656.

39. Ricketts CJ, Forman JR, Rattenberry E et al. Tumor risks and genotype-phenotype-proteotype analysis in 358 patients with germline mutations in SDHB and SDHD. Hum. Mutat. 2010; 31; 41-51.

40. Nijhoff MF, Dekkers OM, Vleming LJ, Smit JW, Romijn JA, Pereira AM. ACTH-producing pheochromocytoma: clinical considerations and concise review of the literature. Eur. J. Intern. Med. 2009; 20; 682-685.

41. Harari A, Inabnet WB. Malignant pheochromocytoma: a review. Am. J. Surg. 2011; 201; 700-708.

42. Korevaar TI, Grossman AB. Pheochromocytomas and paragangliomas: assessment of malignant potential. Endocrine 2011; 40; 354-365.

43. Goffredo P, Sosa JA, Roman SA. Malignant pheochromocytoma and paraganglioma: a population level analysis of long-term survival over two decades. J. Surg. Oncol. 2013; 107; 659664
44. Beilan JA, Lawton A, Hajdenberg J, Rosser CJ. Pheochromocytoma of the urinary bladder: a systematic review of the contemporary literature. BMC Urol. 2013; 13; 22.

45. Dimitriadis GK, Angelousi A, Weickert MO, Randeva HS, Kaltsas G, Grossman A. Paraneoplastic endocrine syndromes. Endocr. Relat. Cancer 2017; 24; R173-R190.

46. Lack EE. Tumors of the adrenal glands and extraadrenal paraganglia. Atlas of tumour pathology, Series 4, Vol. 8. Washington, DC: Armed Forces Institute of Pathology, 2008.

47. Wen J, Li HZ, Ji ZG, Mao QZ, Shi BB, Yan WG. A decade of clinical experience with extra-adrenal paragangliomas of retroperitoneum: report of 67 cases and a literature review. Urol. Ann. 2010; 2; 12-16.

48. Sclafani LM, Woodruff JM, Brennan MF. Extraadrenal retroperitoneal paragangliomas: natural history and response to treatment. Surgery 1990; 108; 1124-1130.

49. Lenders JW, Duh QY, Eisenhofer G et al. Pheochromocytoma and paraganglioma: an endocrine society clinical practice guideline. J. Clin. Endocrinol. Metab. 2014; 99; 19151942.

50. Castinetti F, Kroiss A, Kumar R, Pacak K, Taieb D. 15 years of paraganglioma: imaging and imaging-based treatment of pheochromocytoma and paraganglioma. Endocr. Relat. Cancer 2015; 22; T135-T145.

51. Janssen I, Blanchet EM, Adams K et al. Superiority of [68 Ga]DOTATATE PET/CT to other functional imaging modalities in the localization of SDHB-associated metastatic pheochromocytoma and paraganglioma. Clin. Cancer Res. 2015; 21; 3888 3895.

52. Korpershoek E, Petri BJ, Post E et al. Adrenal medullary hyperplasia is a precursor lesion for pheochromocytoma in MEN2 syndrome. Neoplasia (New York) 2014; 16; 868-873.

53. Eisenhofer G, Lenders JW, Timmers $\mathrm{H}$ et al. Measurements of plasma methoxytyramine, normetanephrine, and metanephrine as discriminators of different hereditary forms of pheochromocytoma. Clin. Chem. 2011; 57; 411-420.

54. Eisenhofer G, Peitzsch M. Laboratory evaluation of pheochromocytoma and paraganglioma. Clin. Chem. 2014; 60; 1486 1499.

55. Osinga TE, Korpershoek E, de Krijger RR et al. Catecholaminesynthesizing enzymes are expressed in parasympathetic head and neck paraganglioma tissue. Neuroendocrinology 2015; 101; 289-295.

56. Carney JA, Sizemore GW, Tyce GM. Bilateral adrenal medullary hyperplasia in multiple endocrine neoplasia, type 2: the precursor of bilateral pheochromocytoma. Mayo Clin. Proc. 1975; 50; 3-10.

57. Shin WY, Groman GS, Berkman JI. Pheochromocytoma with angiomatous features. A case report and ultrastructural study. Cancer 1977; 40; 275-283.

58. Kasem K, Lam AK. Adrenal oncocytic phaeochromocytoma with putative adverse histologic features: a unique case report and review of the literature. Endocr. Pathol. 2014; 25; 416421.

59. Strong VE, Kennedy T, Al-Ahmadie $\mathrm{H}$ et al. Prognostic indicators of malignancy in adrenal pheochromocytomas: clinical, histopathologic, and cell cycle/apoptosis gene expression analysis. Surgery 2008; 143; 759-768.

60. Eisenhofer G, Tischler AS, de Krijger RR. Diagnostic tests and biomarkers for pheochromocytoma and extra-adrenal paraganglioma: from routine laboratory methods to disease stratification. Endocr. Pathol. 2012; 23; 4-14. 
61. Kimura N, Takayanagi R, Takizawa N et al. Pathological grading for predicting metastasis in phaeochromocytoma and paraganglioma. Endocr. Relat. Cancer 2014; 21; 405-414.

62. Thompson LD. Pheochromocytoma of the Adrenal gland Scaled Score (PASS) to separate benign from malignant neoplasms: a clinicopathologic and immunophenotypic study of 100 cases. Am. J. Surg. Pathol. 2002; 26; 551-566.

63. Kimura N, Watanabe T, Noshiro T, Shizawa S, Miura Y. Histological grading of adrenal and extra-adrenal pheochromocytomas and relationship to prognosis: a clinicopathological analysis of 116 adrenal pheochromocytomas and 30 extraadrenal sympathetic paragangliomas including 38 malignant tumors. Endocr. Pathol. 2005; 16; 23-32.

64. Linnoila RI, Keiser HR, Steinberg SM, Lack EE. Histopathology of benign versus malignant sympathoadrenal paragangliomas: clinicopathologic study of 120 cases including unusual histologic features. Hum. Pathol. 1990; 21; 1168-1180.

65. Oudijk L, van Nederveen F, Badoual C et al. Vascular pattern analysis for the prediction of clinical behaviour in pheochromocytomas and paragangliomas. PLOS ONE 2015; 10; e0121361.

66. Unger P, Hoffman K, Pertsemlidis D, Thung S, Wolfe D, Kaneko M. S100 protein-positive sustentacular cells in malignant and locally aggressive adrenal pheochromocytomas. Arch. Pathol. Lab. Med. 1991; 115; 484-487.

67. Kimura N, Takekoshi K, Horii A et al. Clinicopathological study of SDHB mutation-related pheochromocytoma and sympathetic paraganglioma. Endocr. Relat. Cancer 2014; 21; L13-L16.

68. Koch CA, Mauro D, Walther MM et al. Pheochromocytoma in von Hippel-Lindau disease: distinct histopathologic phenotype compared to pheochromocytoma in multiple endocrine neoplasia type 2. Endocr. Pathol. 2002; 13; 17-27.

69. Toledo SP, Lourenço DM, Sekiya T et al. Penetrance and clinical features of pheochromocytoma in a six-generation family carrying a germline TMEM127 mutation. J. Clin. Endocrinol. Metab. 2015; 100; E308-E318.
70. Tischler AS, deKrijger RR. 15 years of paraganglioma: pathology of pheochromocytoma and paraganglioma. Endocr. Relat. Cancer 2015; 22; T123-T133.

71. Duregon E, Volante M, Bollito E et al. Pitfalls in the diagnosis of adrenocortical tumors: a lesson from 300 consultation cases. Hum. Pathol. 2015; 46; 1799-1807.

72. Tischler AS. Pheochromocytoma and extra-adrenal paraganglioma: updates. Arch. Pathol. Lab. Med. 2008; 132; 1272 1284.

73. Asa SL. My approach to oncocytic tumours of the thyroid. J. Clin. Pathol. 2004; 57; 225-232.

74. Lloyd RV, Blaivas M, Wilson BS. Distribution of chromogranin and S100 protein in normal and abnormal adrenal medullary tissues. Arch. Pathol. Lab. Med. 1985; 109; 633-635.

75. Sbiera S, Schmull S, Assie G et al. High diagnostic and prognostic value of steroidogenic factor-1 expression in adrenal tumors. J. Clin. Endocrinol. Metab. 2010; 95; E161-E171.

76. Pacak K, Eisenhofer G, Ahlman H et al. Pheochromocytoma: recommendations for clinical practice from the First International Symposium, October 2005. Nat. Clin. Pract. Endocrinol. Metab. 2007; 3; 92-102.

77. Amar L, Bertherat J, Baudin E et al. Genetic testing in pheochromocytoma or functional paraganglioma. J. Clin. Oncol. 2005; 23; 8812-8818.

78. Brito JP, Asi N, Bancos I et al. Testing for germline mutations in sporadic pheochromocytoma/paraganglioma: a systematic review. Clin. Endocrinol. (Oxf) 2015; 82; 338-345.

79. Neumann HP, Bausch B, McWhinney SR et al. Germ-line mutations in nonsyndromic pheochromocytoma. N. Engl. J. Med. 2002; 346; 1459-1466.

80. Luchetti A, Walsh D, Rodger F et al. Profiling of somatic mutations in phaeochromocytoma and paraganglioma by targeted next generation sequencing analysis. Int. J. Endocrinol. 2015; 2015; 138573.

81. Pacak K, Wimalawansa SJ. Pheochromocytoma and paraganglioma. Endocr. Pract. 2015; 21; 406-412. 